\title{
Conceptualising attributional LCA is necessary for resolving methodological issues such as the appropriate form of land use baseline
}

\author{
Matthew Brander ${ }^{1}$
}

Received: 31 May 2016 / Accepted: 2 June 2016 / Published online: 15 June 2016

(C) The Author(s) 2016. This article is published with open access at Springerlink.com

\begin{abstract}
Purpose The purposes of this commentary are to further an on-going debate concerning the appropriate form of land use baseline for attributional life cycle assessment (LCA) and to respond to a number of arguments advanced by Soimakallio (Int J Life Cycle Assess 20:1364-1375, 2016). The commentary also seeks to clarify the conceptual nature of attributional LCA.

Methods The overarching approach for resolving the question of the appropriate form of land use baseline for attributional LCA is to clarify what attributional LCA is seeking to represent, i.e. methodological questions can only be resolved if it is clear what the method is seeking to do. An illustrative example is used to explore the different results produced by 'natural regeneration' and 'natural' baselines.

Results and discussion It is proposed that attributional LCA should be conceptualised as an inventory of anthropogenic impacts, conceptually akin to other forms of environmental inventory, such as national GHG inventories. The use of natural regeneration baselines is not consistent with this conceptualisation of attributional LCA, and such baselines necessitate further ad hoc or arbitrary adjustments, such as arbitrary temporal windows or the inconsistent treatment of natural emissions.

Conclusions The use of natural regeneration baselines may be motivated by the impulse to make attributional LCA both an
\end{abstract}

Responsible editor: Mary Ann Curran

Matthew Brander

Matthew.Brander@ed.ac.uk

1 Business School, University of Edinburgh, 29 Buccleuch Place, Edinburgh EH8 9JS, UK inventory-type method and an assessment of system-wide change. Pulling attributional LCA in two different directions at once results in a conceptually and methodologically incoherent method. The solution is to recognise attributional LCA as an inventory-type method, which therefore has distinct but complementary uses to consequential LCA, which is an assessment of system-wide change.

Keywords Attributional life cycle assessment - Baselines . Consequential life cycle assessment · Decision-making . National greenhouse gas inventories $\cdot$ Sequestration

\section{Introduction}

This article is the fourth in an exchange of views (the previous being Soimakallio et al. (2015), Brander (2015a), and Soimakallio et al. (2016)), which ostensibly concerns the appropriate type of land use baseline for attributional life cycle assessment (LCA), but at a deeper level concerns the conceptualisation of attributional LCA. These two issues are inextricably linked as the conceptualisation of the method, i.e. what it seeks to represent and what it should be used for, will determine subsequent methodological choices, such as the appropriate form of land use baseline.

This principle of matching methods to purposes is widely recognised in terms of selecting the appropriate method for a given purpose (Zamagni et al. 2012), but it applies equally to developing methods so that they fulfil their intended purpose. It is only by resolving what attributional LCA is for that it is then also possible to resolve methodological issues such as the appropriate form of land use baseline. This approach stands somewhat in contrast to that in Soimakallio et al. (2016), which attempts to resolve a methodological debate while explicitly avoiding the purpose of the method: 
We would like to emphasize that our paper did not aim to engage in the debate on the choice between ALCA and CLCA. Thus, we merely mention that there are arguments for (e.g. Ekvall et al. 2005) and against (e.g. Plevin et al. 2014) the appropriateness of ALCA to support decision-making. We urge researchers to consider which approach best meets the purpose of their study. On the appropriateness of natural regeneration as a landuse baseline in ALCA, we respond to each of Brander's criticism in turn, in order to consolidate our arguments on the issue. (2016, p.1607).

Although the recommendation that researchers should 'consider which approach meets the purpose of their study' is entirely correct, it is also essential to recognise that researchers should consider the intended purpose when developing methods. The present paper proceeds on the basis that methodological questions can only be resolved if it is clear what the method is seeking to do.

To this end, a conceptualisation of attributional LCA is proposed (Section 2); following this, an illustrative example is used to analyse the different information provided by 'natural regeneration' and 'natural' baselines, and a critique of a number of the arguments in Soimakallio et al. (2016) is provided (Section 3); reaching the conclusion that a natural baseline should be used if attributional LCA is to provide a true inventory of anthropogenic impacts.

\section{Conceptualising attributional LCA}

This section proposes how attributional LCA should be conceptualised, i.e. what it seeks to represent and what it should be used for. Much of this interpretation is present, though dispersed, in Brander (2015a), and it is therefore worth gathering the key points to provide a consolidated account.

In essence, attributional LCA is an assessment or inventory of anthropogenic impacts associated with the processes used in the life cycle of a product. The normative rules for determining the inventory boundary are typically based on the physical processes used in producing, consuming and disposing of the product. Attributional LCA can be considered conceptually equivalent to other forms of environmental inventory, such as national greenhouse gas inventories (IPCC 2006), which count the anthropogenic emissions/removals that occur within a normatively defined boundary, in this case, the geographical boundary of a country. ${ }^{1}$ Attributional LCA operates in largely the same way, but instead of counting anthropogenic

\footnotetext{
${ }^{1}$ Though as noted in Brander (2015a), national inventories do not currently include foregone sequestration, despite this being an anthropogenic impact, and the methodological advancements proposed within the life cycle assessment literature could usefully be transposed to national inventory accounting.
}

impacts for a country, it counts the anthropogenic impacts for a product. The same conceptual model applies to community greenhouse gas inventories (Schultz et al. 2014; British Standards Institute 2013) and corporate greenhouse gas inventories (WBCSD/WRI 2004; ISO 2006b). All these methods count impacts within a normatively defined inventory boundary, and they are just doing so for different levels of entity, i.e. they are simply setting the inventory boundary in different ways (Brander 2015b).

Now, given this conceptualisation of what attributional LCA is, it is also possible to state what it can be appropriately used for. Firstly, as previously described in Brander (2015a), it can be used for assigning unique responsibility or ownership for the management of a set of impacts, as is the case, for example, with national inventories under the UNFCCC (United Nations 1992). Similarly, consumers can take ownership of the attributionally defined life cycle impacts of the products they consume, as is the case with consumptionbased carbon accounting (Barrett et al. 2013). Secondly, and relatedly, attributional LCA can be used to set reduction targets, e.g. if a company knows that the life cycle emissions of its product are $2 \mathrm{~kg} \mathrm{CO}_{2} \mathrm{e} / \mathrm{unit}$, then it can specify a reduction target, e.g. to achieve $1 \mathrm{~kg} \mathrm{CO}_{2}$ e/unit by a specified date. Thirdly, attributional LCA can be used to allocate environmental impact budgets (e.g. personal carbon allowances (Carbon Trust 2012)) to ensure that total impacts do not exceed an aggregate threshold level. It is worth noting that this use of attributional LCA requires adherence to the additivity principle whereby 'LCA results of all the products in the world should add up to the total environmental impact in the world' (Tillman 2000, p.117), not only within a specific temporal window but also over time.

As well as this positive account of what attributional is and what it can be used for, it is also useful to provide a negative account of what it is not, and what it cannot be used for. Attributional LCA does not provide information on the total change in environmental impacts caused by a specified decision, i.e. the normative boundary-setting rules in attributional LCA do not necessarily capture or reflect all the processes that will change (Plevin et al. 2014). If we accept that good decision-making should be informed by consideration of the consequences of the decision, then it follows that attributional LCA is not sufficient for informing decision-making, as, conceptually and methodologically, it does not provide such information.

Proponents of attributional LCA for decision-making need to challenge either or both of the premises above: (a) attributional LCA does not provide information on the total change in environmental impacts caused by a decision, and (b) decisions should be informed by consideration of all the consequences caused. It may be suggested that attributional LCA can, on occasion, provide a reasonable proxy for total change in impacts (Lundie et al. 2007; Yang and Church 2016), but 
the counter argument is that unless we use an alternative method to check this approximation, we will not know if the attributional method has omitted important impacts, in which case it would be more efficient to only use the alternative method in the first place (Zamagni et al. 2012). Alternatively, it may be argued that attributional LCA can be used for decision-making, if the decision-making relates to purposes such as assigning unique responsibility for a set of impacts, etc. Here it is important to clarify that attributional LCA is not sufficient for decision-making regarding mitigation actions, including the archetypal LCA decision scenario of choosing between alternative products (ISO 2006a). However, attributional LCA can be used for making other kinds of decisions, related to assigning responsibility etc., which are not mitigation actions in themselves, i.e. they do not directly reduce environmental impacts.

There are a number of positive implications from the conceptualisation of attributional LCA presented above. It offers a resolution to the long-running debate over the appropriate use of attributional and consequential LCA (Weidema 2003; Plevin et al. 2014). Attributional LCA is appropriate for assigning responsibility for a set of impacts, setting reduction targets, or allocating impact budgets, and none of these functions can be fulfilled by a consequential LCA. For instance, consequential LCA cannot be used to assign responsibility for managing a set of impacts, as the number of decisions an entity makes is practically intractable, and the system-wide impacts from those decisions are dispersed and overlap with the impacts caused by other entities' decisions. This largely answers the contention that there is no purpose for which consequential LCA would not be more appropriate (Wenzel 1998). Consequential LCA, which does aim to provide information on total impacts caused by decisions, can be seen as complementary to attributional LCA, by informing decisions aimed at reducing impacts within an attributionally assigned sphere of responsibility or decisions aimed at achieving attributionally defined reduction targets.

It is highly important to recognise these two fundamentally distinct forms of environmental assessment: inventories of anthropogenic impacts on the one hand and assessments of system-wide change on the other. They are two distinct types of method, with different but complementary uses. The reason for emphasising this point is that much of the debate and confusion over the nature and use of attributional LCA appears to arise because the method is expected to fulfil both these distinct functions at once. Something of this nature may underlie the motivation for using natural regeneration baselines in attributional LCA, and this point is revisited in the concluding section.

With the suggested conceptualisation of attributional LCA in place, it is now possible to address the methodological issue of the appropriate form of land use baseline for attributional LCA.

\section{The appropriate form of natural baseline for attributional LCA}

There is apparent agreement that a land use baseline is necessary in order to identify anthropogenic impacts, but disagreement arises over whether a natural regeneration baseline, advocated by Soimakallio et al. $(2015 ; 2016)$, or a natural baseline, advocated by Brander (2015a), is the most appropriate for attributional LCA. These two baseline options can be described as follows:

1. A natural regeneration baseline represents the amount of sequestration that would occur if anthropogenic land occupation ceased, e.g. through the abandonment of agricultural land.

2. A natural baseline represents the amount of sequestration that would occur if there had been no anthropogenic activities at all.

The difference in the results produced by these two alternative options can be explored using the following illustrative example, developed from the example in Brander (2015a): (1) At some point in the past, terrestrial carbon stocks accumulated as the ecosystem sequestered $\mathrm{CO}_{2}$ from the atmosphere, with the annual on-going rate of sequestration stabilising at $1 \mathrm{tCO}_{2} /$ ha year, i.e. the ecosystem would continue sequestering carbon indefinitely at a rate of $1 \mathrm{tCO}_{2}$ /ha year (see for example Luyssaert et al. (2008)). (2) However, at a certain point, anthropogenic land use change occurred, e.g. forest land was converted to agricultural use, emitting $100 \mathrm{tCO}_{2}$. (3) The continued cultivation of the land means that it does not revert to a natural state, and the on-going rate of sequestration is zero. (4) If natural regeneration were to occur, it would re-sequester the $100 \mathrm{tCO}_{2}$ over a 20 -year period, after which the rate of on-going sequestration would also continue at $1 \mathrm{tCO}_{2}$ /ha year. Figure 1 provides a graphical representation of this illustrative example.

It is now possible to analyse the different results for foregone sequestration from these two different baseline options (with foregone sequestration calculated by subtracting the level of sequestration in the baseline from the amount of sequestration in the 'with product' scenario). For the natural regeneration baseline, assuming a 20-year assessment period, the amount of foregone sequestration would be $-100 \mathrm{tCO}_{2}(0$ $\left.100 \mathrm{tCO}_{2}\right){ }^{2}$ For the natural baseline, the amount of foregone sequestration would be $-20 \mathrm{tCO}_{2}\left(0 \mathrm{tCO}_{2}-20\right.$ years $* 1 \mathrm{tCO}_{2} /$ ha year). Clearly, the two forms of baseline produce different results and represent different aspects of environmental impact

\footnotetext{
${ }^{2}$ Sequestration is represented as a positive number, and so foregone sequestration is represented by a negative number, i.e. $-100 \mathrm{tCO}_{2}$ means there is a loss of sequestration. This also entails that the amount of $\mathrm{CO}_{2}$ in the atmosphere is $100 \mathrm{tCO}_{2}$ more than it otherwise would have been.
} 
Fig. 1 Illustrative example comparing natural regeneration and natural baselines

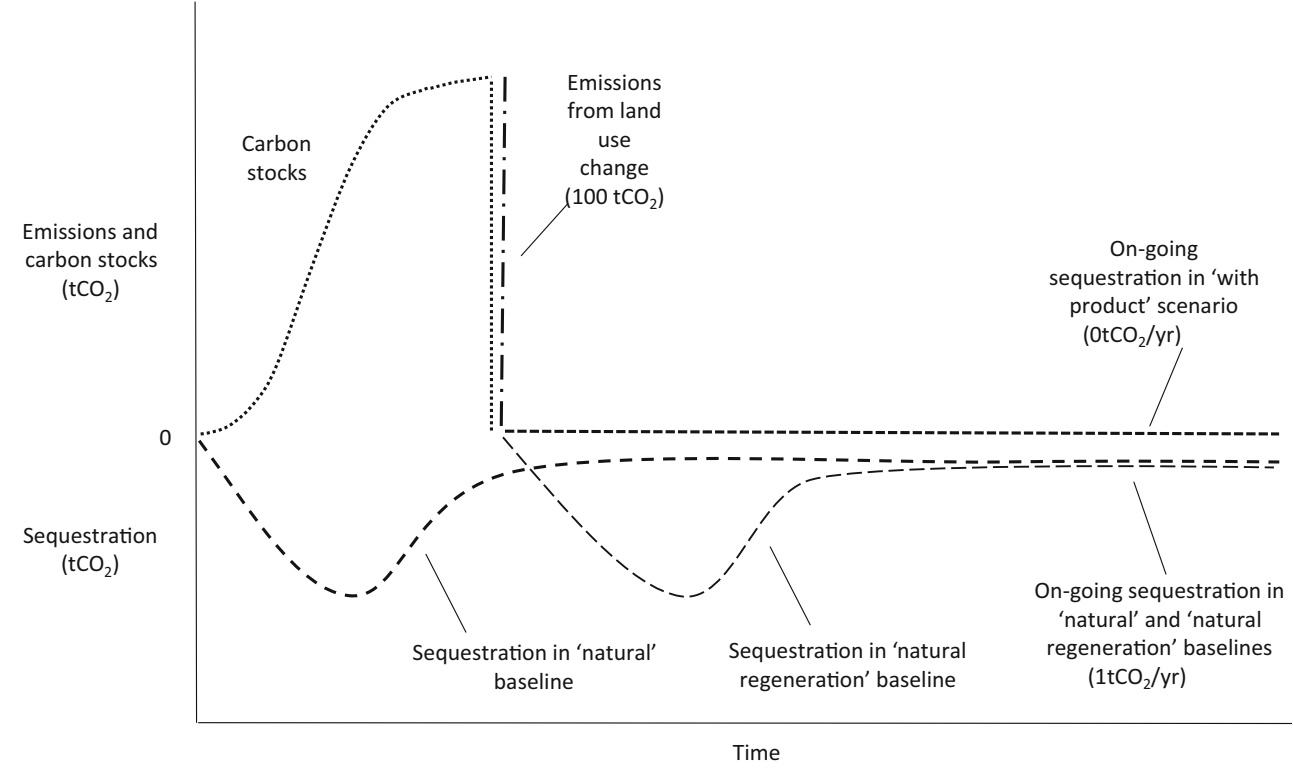

or change, which in turn affects what the results can be used for.

The results from the natural baseline represent the total amount of sequestration foregone, during the 20 -year assessment period, due to anthropogenic activities, i.e. relative to what would have happened in the absence of all human activity. Another way of thinking about this is to imagine a simplified world in which the only human activities are the land use change and the on-going cultivation of the land in the illustrative example: if we consider the 20-year period following the land use change, the total anthropogenic impact is $120 \mathrm{tCO}_{2}\left(100 \mathrm{tCO}_{2}\right.$ emissions from the land use change $+20 \mathrm{tCO}_{2}$ from foregone sequestration), i.e. the total amount of greenhouse gases in the atmosphere would be $120 \mathrm{tCO}_{2}$ less in the absence of human influence. This information can be used for allocating environmental budgets which restrict total cumulative impacts below a specified aggregate level.

Turning to the natural regeneration baseline, the results represent the amount of foregone sequestration relative to what would have happened if humans stopped cultivating the land. Considering our simplified world again, and the same 20-year period, the $100 \mathrm{tCO}_{2}$ figure for foregone sequestration cannot be aggregated with the $100 \mathrm{tCO}_{2}$ figure for land use change emissions to represent total cumulative anthropogenic impacts. This also means that the results cannot be used for purposes such as allocating environmental budgets which restrict total impacts below a specified aggregate level, and the use of a natural regeneration baseline is not consistent with the conceptualisation of attributional LCA outlined earlier.

Clearly, if an alternative conceptualisation of attributional LCA is offered then the 'natural regeneration' baseline may be appropriate, but in order to make this argument, a clear statement is needed on what that alternative conceptualisation is. In addition to demonstrating the consistency of natural baselines with the suggested conceptualisation of attributional LCA, the illustrative example above is also useful for analysing a number of the arguments in Soimakallio et al. (2016).

Firstly, Soimakallio et al. suggest that a "natural or quasinatural steady state can be used as the baseline when the studied land use starts from the initial LUC [land use change]' but that 'if the historic LUC has been attributed to previous land use and not to the studied land use...the link between the studied land use and the earlier natural state is lost, which makes the application of natural state as land-use baseline incoherent' (2016, p.449). However, it appears to be wholly irrelevant whether the studied land use starts from the initial LUC or not. In order to estimate the level of foregone sequestration, the researcher needs to calculate the difference between the baseline and the 'with product level' of sequestration, and the timing or presence of any preceding LUC does not enter into the calculation. Calculating and allocating any LUC emissions is an entirely separate exercise.

Secondly, in order to address the way in which natural regeneration baselines double-count the same foregone sequestration in perpetuity (as the same potential for regeneration will be applied to successive product systems using the land), Soimakallio et al. suggest that if we interpret attributional LCA as 'requiring additivity only within the given temporal window, then the fact that LCA results are not additive across temporal windows is not an inconsistency' (2016, p.449). However, this appears to concede a major limitation in the potential use of attributional LCA. Many environmental impacts, not least greenhouse gas emissions, are cumulative over long periods of time, and temporal additivity is therefore important, e.g. attributional LCA could not be used for allocating carbon budgets if temporal additivity is conceded. Moreover, the introduction of 'temporal windows' introduces 
an unnecessarily arbitrary element into the method, i.e. how long should the temporal window be before we double-count the same quantity of foregone sequestration again?

Soimakallio et al. (2016) suggest that temporal additivity could be maintained by 'considering the full life-cycle interventions related to land use, i.e. from the beginning of land occupation until the point when land has been fully returned to its natural state after land occupation...the carbon flows balance (i.e. net carbon emissions between the studied land use and its baseline) is zero, given there is no net loss or gain in $\mathrm{C}$ stocks' (p.449). It would be useful to see greater detail for how this proposal would work; however, there are a number of apparently problematic issues: (a) it requires retrospectively estimating what might be highly historic LUC emissions and any intervening forgone sequestration and the equivalent exercise prospectively to the point when land returns to a natural state, whereas the use of a natural baseline will avoid doublecounting of foregone sequestration simply by using the natural baseline for the period of time that the studied product occupies the land; (b) the carbon flows may never balance, i.e. if there is on-going natural sequestration, as in the illustrative example, the 'with product' carbon stocks will always lag behind, even after the land is returned to a natural state; and (c) it is not clear how this approach would cope with cases in which the land is never returned to a natural state.

Thirdly, the argument that natural regeneration is the 'most natural process taking place if land occupation ceases' (Soimakallio et al. 2016, p.448) appears to introduce inconsistencies with the way other equally natural processes are treated. For example, the anaerobic decay of organic waste within a landfill site is an equally natural process, i.e. it is what would occur if all human activity ceased. Emissions from waste also mirror the case with natural regeneration, in that the potential for emissions/removals is entirely created by human activities (i.e. waste disposal and land use change respectively). If a consistent rationale is applied to both cases, then a product system which captures the landfill emissions that would otherwise have been emitted to the atmosphere (i.e. compared to a natural degeneration baseline) could claim a credit for reducing natural emissions. It is hard to accept that the avoidance of landfill waste emissions is an anthropogenic impact, as landfill waste emissions are not a nonanthropogenic environmental flow, but if we are to be consistent with the use of natural regeneration baselines, it appears we must.

One reason why natural regeneration baselines may appear to be appropriate is due to the ambiguity around the terms 'natural' and 'human-induced impact'. The escape of methane from a landfill site is natural in the sense that it would occur if all human activity ceased, and the avoidance of the release of methane is a human-induced impact in the sense that it requires human involvement. But the escape of methane is not natural, in the sense that it would not have happened if humans had not disposed of the waste in the first place. It is this latter sense that is intended when separating anthropogenic from non-anthropogenic environmental impacts, and when calculating true inventories of anthropogenic impacts.

\section{Conclusions}

Soimakallio et al. conclude that 'land occupation (i.e. postponing natural regeneration) causes environmentally relevant physical flows, and their impacts need to be considered for any ALCA in which land use is a resource flow, in order to avoid misleading results.' (2016, p.449). The key question here is 'Misleading for what?', i.e. we need to conceptualise what the results are intended to represent, and what they are intended to be used for, before we can judge whether they are misleading or not. The results may be misleading if they are intended to answer questions such as 'What are the total impacts from the decision to continue using this land?', but, as argued earlier, that is properly a question for consequential LCA. ${ }^{3}$ The results will not be misleading if a natural rather than natural regeneration baseline is used, and the intention is separate anthropogenic from non-anthropogenic environmental impacts.

There appears to be a presupposition within Soimakallio et al.'s concluding argument that attributional LCA should be relevant for informing mitigation decisions, and the argument provides a good illustration of the impulse to make attributional LCA both an inventory-type method and an assessment of system-wide change caused by a decision. Pulling attributional LCA in two different directions at once creates a method that is neither a true inventory of anthropogenic impacts nor a comprehensive assessment of system-wide change. This conceptual incoherence is like a piece out of place in a jigsaw puzzle, which then requires numerous ad hoc or arbitrary adjustments to maintain some semblance of order, such as arbitrary temporal windows, or the inconsistent treatment of 'natural' emissions.

The solution proposed in this paper is to recognise attributional LCA as an inventory of anthropogenic impacts, conceptually akin to other forms of environmental inventory. If this conceptualisation is recognised then attributional and consequential LCA can be seen as distinct but wholly complementary methods, each with their own set of appropriate uses.

\footnotetext{
${ }^{3}$ Soimakallio et al. (2016) make the point that the baseline used in consequential LCA should be the most likely alternative land use, which may not necessarily be natural regeneration. This is entirely correct, but it is worth clarifying that Brander (2015a) did not suggest otherwise, but rather made the point that the aim of capturing the consequences of land occupation belongs to a consequential perspective. Attributional LCA should be concerned with separating anthropogenic from nonanthropogenic environmental impacts.
} 
Acknowledgments Matthew Brander would like to thank Sampo Soimakallio and his co-authors for this stimulating and cordial debate and would also like to acknowledge the UK's Economic and Social Research Council (ESRC), in partnership with the Society for the Advancement of Management Studies (SAMS) and the UK Commission for Employment and Skills (UKCES), for their support through the Management and Business Development Fellowship Scheme.

Open Access This article is distributed under the terms of the Creative Commons Attribution 4.0 International License (http:// creativecommons.org/licenses/by/4.0/), which permits unrestricted use, distribution, and reproduction in any medium, provided you give appropriate credit to the original author(s) and the source, provide a link to the Creative Commons license, and indicate if changes were made.

\section{References}

Barrett J et al (2013) Consumption-based GHG emission accounting: a UK case study. Clim Pol 13(4):451-470

Brander M (2015a) Response to "attributional life cycle assessment: is a land-use baseline necessary?"- appreciation, renouncement, and further discussion. Int J Life Cycle Assess 20(12):1607-1611

Brander M (2015b) Transposing lessons between different forms of consequential greenhouse gas accounting: lessons for consequential life cycle assessment, project-level accounting, and policy-level accounting. J Clean Prod 112:4247-4256

British Standards Institute (2013) PAS 2070 - specification for the assessment of greenhouse gas emissions of a city. British Standards Institute, London

Carbon Trust (2012) Personal carbon allowances - white paper. London

Ekvall, T., Tillman, A.-M. \& Molander, S., 2005. Normative ethics and methodology for life cycle assessment. J Clean Prod, 13(13-14), pp.1225-1234

IPCC (2006) IPCC guidelines for national greenhouse gas inventories. In: HS Eggleston et al. (eds.) IGES, Japan: Intergovernmental Panel on Climate Change

ISO (2006a) ISO 14044 environmental management — life cycle assessment - requirements and guidelines. Geneva
ISO (2006b) ISO 14064-1-Specificiation with guidance at the organization level for quantification and the reporting of greenhouse gas emissions and removals. Geneva

Lundie S, Ciroth A, Huppes G (2007) Inventory methods in LCA : towards consistency and improvement. Available at: file://C:/Users/ mbrander/Downloads/070610 TF3 Inventory methods in LCA final report.pdf

Luyssaert S et al (2008) Old-growth forests as global carbon sinks. Nature 455(7210):213-215

Plevin RJ, Delucchi M, Creutzig F (2014) Using attributional life cycle assessment to estimate climate-change mitigation benefits misleads policy makers. J Ind Ecol 18(1):73-83

Schultz S et al. (2014) Global protocol for community-scale greenhouse gas emissions inventories - version 2.0, Geneva, Switzerland and Washington, DC, USA. Available at: http://www.ghgprotocol. org/files/ghgp/GPC Draft 2.0 for public comment.pdf

Soimakallio S et al (2015) Attributional life cycle assessment: is a landuse baseline necessary? Int J Life Cycle Assess 20(10):1364-1375

Soimakallio $\mathrm{S}$ et al (2016) On the validity of natural regeneration in determination of land-use baseline. Int J Life Cycle Assess, Letters to the Editors, 21(4):448-450

Tillman A-M (2000) Significance of decision-making for LCA methodology. Environ Impact Assess Rev 20(1):113-123

United Nations (1992) United Nations Framework Convention on Climate Change. Available at: http://unfccc.int/files/essential background/background publications htmlpdf/application/ pdf/conveng.pdf

WBCSD/WRI (2004) Greenhouse gas protocol: a corporate accounting and reporting standard. Geneva, Switzerland and Washington, DC, USA

Weidema B (2003) Market information in life cycle assessment. Danish Environmental Protection Agency, Copenhagen

Wenzel H (1998) Application dependency of LCA methodology: key variables and their mode of influencing the method. Int $\mathrm{J}$ Life Cycle Assess 3(5):281-288

Yang Y, Church F (2016) Two sides of the same coin: consequential life cycle assessment based on the attributional framework. J Clean Prod 127:1-15

Zamagni A et al (2012) Lights and shadows in consequential LCA. Int J Life Cycle Assess 17(7):904-918 